\title{
The Treatment for Postirradiation Otitis Media With Effusion: A Study of Three Methods
}

\author{
Yao-Dong Xu, MD; Yong-Kang Ou, MD; Yi-Qing Zheng, MD; Yong Chen, MD; Shu-Fang Ji, MD
}

Objective: To explore treatments for postirradiation otitis media with effusion (OME) in patients with nasopharyngeal carcinoma.

Study Design: This study is a prospective quasirandomized clinical trial.

Methods: Ninety-six patients (135 ears) with OME after the first course of radiotherapy for nasopharyngeal carcinoma were divided into three groups: simple auripuncture plus aspiration, tympanic membrane fenestration with cauterization, and myringotomy plus grommet insertion. Cure rates and incidences of complications were compared.

Results: Two deaths occurred. The other 94 patients (132 ears) finished a 2-year follow-up. In group 1, four ears $(8.9 \%)$ were cured after the first treatment and 17 ears overall $(37.8 \%)$ were cured by the end of the follow-up. Twenty ears (44.4\%) had persistent fluid, two ears $(4.4 \%)$ developed chronic suppurative otitis media, and five ears (11.1\%) developed dry eardrum perforation. In group 2, seven ears (15.6\%) were cured after the first treatment and 21 ears overall $(46.7 \%)$ were cured by the end of the follow-up. Fourteen ears (31.1\%) had persistent fluid, three ears (6.7\%) developed chronic suppurative otitis media, and seven ears $(15.6 \%)$ developed dry eardrum perforation. In group 3, eight ears (17.8\%) were cured after the first treatment and 23 ears overall (51.1\%) were cured by the end of the follow-up. Seven ears (15.6\%) had persistent fluid, five ears $(11.1 \%)$ developed chronic suppurative otitis media, three ears (6.7\%) developed eardrum perforation with effusion, and five ears (11.1\%) developed dry eardrum perforation.

Conclusion: The methods each have advantages and disadvantages. We believe that a step by step approach should be used when choosing the treatment method for postirradiation OME. That is, first apply

From the Department of Otolaryngology (Y.-D.X., Y.-K.O., Y.-Q.Z., S.-F.J.), Second Affiliated Hospital of Sun Yat-Sen University, Guangzhou, China and Department of Radiotherapy (Y.c.), the Cancer Center of Sun Yat-Sen University, Guangzhou, China. 3,2008 .

Editor's Note: This Manuscript was accepted for publication June

Send correspondence to Yong-Kang Ou, MD, Yan Jiang Road 107\#, Guangzhou 510120, China. E-mail: yongkang_ou@yahoo.com.cn

DOI: 10.1097/MLG.0b013e31818208d6 auripuncture plus aspiration, and then the other methods if this approach is inadequate. Enhanced local care after grommet insertion can effectively reduce the incidence of complications.

Key Words: Nasopharyngeal carcinoma, otitis media with effusion, radiotherapy, treatment method.

Laryngoscope, 118:2040-2043, 2008

\section{INTRODUCTION}

Nasopharyngeal carcinoma (NPC) is a common cancer in the population of southern China, and radiotherapy is the primary treatment method because of NPCs deep anatomic location, high incidence of lymphatic metastases, and poor pathological differentiation. Temporal bone is unavoidably included in the radiation filed, so various otologic complications, such as otitis externa, otitis media with effusion, chronic otitis media, osteoradionecrosis of the temporal bone, and sensorineural hearing loss (HL), are common occurrences after radiotherapy for NPC. Of these complications, postirradiation OME is the most common and its morbidity is as high as $9 \%$ to $26 \% .^{1}$ Its treatment is difficult, but methods include auripuncture plus aspiration, and tympanic membrane fenestration with a laser and grommet insertion, which are similar to those used in treating conventional OME. Controversy exists as to whether to adopt grommet insertion in postirradiation OME. Those who oppose the method point to the high incidence of complications, especially persistent otorrhea and eardrum perforation. Some even regard the method as contraindicated in postirradiation OME and have advocated auripuncture instead because of its low incidence of complications. ${ }^{2}$ However, according to our clinical experience and observation, the major problem in treating postirradiation OME is not only the high incidence of complications but also the high relapse rate. OME is apt to recur after treatment by simple auripuncture plus aspiration, so that patients do not obtain persistent relief from symptoms. Additionally, many studies ${ }^{2-5}$ emphasize the improvement in hearing and the low incidence of complications when assessing the therapeutic effect of a treatment method. By that standard, a hearing aid is the best choice for OME. However, aural fullness caused by fluid in 
the middle ear and accompanying tinnitus, dizziness, and headache are the most common complaints in patients with NPC. Thus, we should adopt a different standard from that of conventional OME, just as the pathogenesis is different, and consider the balance between the cure rate and the incidence of complications when we assess the effects of treatment methods.

\section{MATERIALS AND METHODS}

\section{General Information}

This study involved 96 patients with NPC (57 men, 39 women) with intact clinical data from October 2000 to February 2006 in the Department of Otolaryngology of the Second Affiliated Hospital and the Cancer Center of Sun Yat-sen University. Fifty-seven (57/96, 59.4\%) unilateral ears and 39 (39/96, 40.6\%) bilateral ears, 135 ears in total, were treated. Ages ranged from 23.5 to 66 years (mean, 48.8). Eighty-nine patients were diagnosed with poorly differentiated squamous cell carcinoma and seven patients had vesicular nucleus cell carcinoma. According to the TNM staging, 27 patients were in stage I, 42 in stage II, 23 in stage III, and four in stage IV. All patients received a course of radiotherapy, with a radiation dosage of 65 to 85 Gy in the nasopharynx and 50 to 70 Gy in the cervical lymph nodes.

To reduce interfering factors because of the different pathogenesis of pre- and postirradiation otitis media with effusion (OME), no patients had complaints about their ears. Additionally, otoscopy, audiometry, and tympanometry were performed to confirm that all patients were free of OME before radiotherapy. There were 123 ears (91.1\%) with type A tympanogram and 12 ears (8.9\%) with type C. The middle ear pressure of ears with type A tympanogram ranged from +5 to -49 dapa (mean -41 , SD 12 ) and the pressure of type $\mathrm{C}$ raged from -50 to -98 dapa (mean -68 , SD 24 ).

The patients had different otologic problems after radiation, including aural fullness in 135 ears (100\%), HL in 87 ears $(90.6 \%)$, tinnitus in 41 ears $(42.7 \%)$, and vertigo in 2 ears $(1.5 \%)$. Eleven ears showed symptoms during radiotherapy, 15 ears 1 week later, 22 ears 3 months later, 32 ears 6 months later, and 16 ears 1 year after the radiotherapy was complete. All patients were diagnosed with OME through otoscopy, audiometry, and tympanometry. And all of them were confirmed having fluid via auripuncture at the beginning of the treatment. One hundred nineteen ears $(88.1 \%)$ were type B tympanogram and 16 ears (11.9\%) type $\mathrm{C}$, which middle ear pressure raged from -180 to -320 dapa(mean -198, SD 40).

The unit of this study is ear. There were three groups in study and we divided the 135 ears into these groups as the orders of patients' receiving treatment. If both ears of a patient were diseased, sortition was used to determine their sequence. The general information of each group is indicated in the Table I below, and three groups prove homogenous using variance analysis and $\chi^{2}$ test.

\section{Treatment Methods}

We adopted the following treatment method for each group.

Group 1: Auripuncture plus aspiration only. Puncture in the lower anterior quadrants of the tympanic membrane and aspirate the fluid in the middle ear.

Group 2: Tympanic membrane fenestration with cauterization. Auripuncture plus aspiration followed by enlargement of the perforation to $1.5 \mathrm{~mm}$ diameter with $30 \%$ trichloroacetic acid.

Group 3: Myringotomy plus grommet insertion. Auripuncture plus aspiration followed by actiniform myringotomy in the lower anterior quadrants of the tympanic membrane. Silica gel ventilation tube was then inserted in the middle ear.

All treatments were performed under a microscope. All ears received repeated washings with mix of $5 \mathrm{mg} \alpha$-chymotrypsin and $5 \mathrm{mg}$ dexamethasone and aspiration with negative pressure simultaneously. Washing of the nasal cavity and nasopharynx was performed in patients with sinusitis or scabs accumulating in the nasopharynx. The same treatments were repeated for the patients with recurrent $\mathrm{OME}$ after the original operations during the 2-year follow-up.

\section{Criteria for Cure}

The criteria for a cure included disappearance of aural fullness, no physical sign of fluid in the middle ear under an endoscope, and a type A tympanogram.

\section{RESULTS}

\section{Group 1}

Except for one ear, because the patient died of recurrent NPC, all finished the 2-year follow-up. Four ears $(8.9 \%)$ were free of disease after the first treatment. The other 40 ears $(88.9 \%)$ had recurrent OME and needed repeated treatments. Times of treatments ranged from 3 to 21 (mean 10.8), and the duration of symptom relief ranged from 1 to 82 days (mean 7.4 days). At the end of the follow-up, 17 ears (37.8\%) were free of disease, 20 ears $(44.4 \%)$ had persistent secretions in the middle ear, and seven ears $(15.6 \%)$ developed chronic otitis media, including two ears $(4.4 \%)$ with suppurative eardrum perforation and five ears $(11.1 \%)$ with dry eardrum perforation. The intact tympanic membranes (22 ears) showed different pathological changes: four tympanic membranes thickened, losing their normal landmarks; eight were in grade II atelectasis (Sadé grade ${ }^{6}$ ), five in grade III, and five in grade IV, adhesive otitis media at least partly. No cholesteatoma was observed.

TABLE I.

General Information of the 135 Ears Before Treatment.

\begin{tabular}{|c|c|c|c|c|c|c|c|c|c|c|}
\hline & \multirow[b]{2}{*}{ Number } & \multirow[b]{2}{*}{ Age $(Y r)$} & \multicolumn{2}{|c|}{ Gender } & \multicolumn{4}{|c|}{ Stage of NPC } & \multicolumn{2}{|c|}{ Tympanogram } \\
\hline & & & Male & Female & 1 & II & III & IV & B & $\mathrm{C}$ \\
\hline Group 1 & 45 & $45 \pm 6$ & 31 & 14 & 11 & 18 & 14 & 2 & 38 & 7 \\
\hline Group 2 & 45 & $43 \pm 7$ & 26 & 19 & 12 & 19 & 10 & 4 & 40 & 5 \\
\hline Group 3 & 45 & $48 \pm 7$ & 28 & 17 & 10 & 22 & 11 & 2 & 41 & 4 \\
\hline$P$-value* & \multicolumn{2}{|r|}{.25} & \multicolumn{2}{|c|}{.547} & \multicolumn{4}{|c|}{.883} & \multicolumn{2}{|c|}{.609} \\
\hline Statistics & & Variance analysis & \multicolumn{2}{|c|}{$\chi^{2}$ test } & \multicolumn{4}{|c|}{$\chi^{2}$ test } & \multicolumn{2}{|c|}{$\chi^{2}$ test } \\
\hline
\end{tabular}

${ }^{*} \alpha=0.05$. 
TABLE II.

Clinical and Statistical Outcomes of the Three Treatment Methods.

\begin{tabular}{lcccc}
\hline & $\begin{array}{c}\text { Cure Rate After the } \\
\text { First Treatment }\end{array}$ & $\begin{array}{c}\text { Cure Rate at the End } \\
\text { of the Follow-Up }\end{array}$ & $\begin{array}{c}\text { Rate of Persistent } \\
\text { Secretions }\end{array}$ & $\begin{array}{c}\text { Incidence } \\
\text { of Complications }\end{array}$ \\
\hline Group 1 (\%) & 8.9 (4 ears) & $37.8(17$ ears $)$ & $44.4(20$ ears) & 15.6 (7 ears) \\
Group 2 (\%) & 15.6 (7 ears) & 46.7 (21 ears) & 31.1 (14 ears) & 22.2 (10 ears) \\
Group 3 (\%) & 17.8 (8 ears) & 51.1 (23 ears) & $15.6(7$ ears) & 28.9 (13 ears) \\
$P_{\text {-value* }}^{*} \chi^{2}$ test) & $P=0.451$ & $P=0.062$ & $P_{1,2}=0.368$ & \\
& & $P_{1,3}=.011$ & $P_{2,3}=.25$ & \\
\hline \hline
\end{tabular}

${ }^{*} \alpha=0.05$

\section{Group 2}

All patients in group 2 finished the 2-year follow-up. Seven ears $(15.6 \%)$ were cured after the first treatment. The other 38 ears $(84.4 \%)$ had recurrent OME and required repeated treatments. Times of treatments ranged from two to five (mean 2.8), and the duration of symptom relief ranged from 8 to 29 days (mean 16.8 days). At the end of the follow-up period, 21 ears (46.7\%) were free of disease, 14 ears $(31.1 \%)$ had persistent secretions in the middle ear, and 10 ears $(22.2 \%)$ developed chronic otitis media, including three ears $(6.7 \%)$ with eardrum perforation and suppuration and seven ears (15.6\%) with dry eardrum perforation. The intact tympanic membranes (10 ears) showed different pathological changes: two tympanic membranes thickened, losing their normal signs; five tympanic membranes were in grade II atelectasis, two in grade III, and one in grade IV, adhesive otitis media at least in part. No cholesteatoma was observed.

\section{Group 3}

Except for 2 ears because the two patients died of recurrent NPC, others all finished the 2-year follow-up. Eight ears (17.8\%) were cured after the first treatment, in which ventilation tubes dropped spontaneously among 6 months or were removed at 6 months. The indwelling time of the grommets ranged from 3 weeks to 6 months. Thirtyfive ears $(77.8 \%)$ required repeated myringotomy plus grommet insertion because of the recurrent OME after the tympanic membranes healed. Times of repeat treatments ranged from one to three (mean 1.6), and the duration of symptom relief ranged from 3 weeks to 1 year (mean 104 days). Nineteen ears $(42.2 \%)$ had otorrhea during the period with ventilation tubes, including suppurative otorrhea in 13 ears (28.9\%) and exudative otorrhea in six (13.3\%). Among the 13 ears with suppurative otorrhea, granulation tissue was found around the inner openings of ventilation tubes in four ears, and these ears became dry after we removed the granulation tissue. In the six ears with exudative otorrhea, we washed the tympanic cavities with drugs repeatedly to relieve symptoms. At the end of the follow-up period, 23 ears (51.1\%) were free of disease, seven ears $(15.6 \%)$ had persistent secretions in the middle ear, and 13 ears (28.9\%) developed chronic otitis media, including five ears $(11.1 \%)$ with eardrum perforation and suppuration, three ears $(6.7 \%)$ with eardrum perforation and secretions, and five ears $(11.1 \%)$ with dry eardrum perforation. The intact tympanic membranes (eight ears) showed different pathological changes: three tympanic membranes thickened, losing their normal landmarks, and three were in grade II atelectasis and two in grade III. Neither adhesive otitis media nor cholesteatoma was observed (Table II).

\section{DISCUSSION}

The pathogenesis of postirradiation OME in patients with NPC is unclear. It may involve direct radiation damage to the structures of the middle ear, including the mucosa and blood and lymphatic vessels, which causes sterile inflammation of the mucosa, makes tissue fluid increase and obstructs its recirculation. ${ }^{4}$ Radiation damage to the eustachian tube and the structures around it, such as cartilage, cilium, the tensor veli palatini muscle, and its nerves, may influence the tubal functions. Tubal dysfunction leads to negative pressure and obstructs drainage of secretions from the middle ears. Low ${ }^{5}$ observed that the negative pressure in the middle ears of patients with NPC after radiotherapy was much higher than normal, and Young's study indicated that the functional impairment of the eustachian tube was irreversible when the radiation dosage was more than $70 \mathrm{~Gy} .{ }^{7}$ Inflammation is also an issue. Radiation inevitably weakens the immunity of local tissues around the middle ear and causes nasopharyngitis, rhinitis, and sinusitis. Such inflammation aggravates the inflammatory reaction in the middle ear and the eustachian tube..$^{2,7}$

So the primary cause of postirradiation OME is direct radiation damage, but conventional $\mathrm{OME}$ is primarily caused by affection of the eustachian tube. Patients with conventional OME can get satisfactory results with the usual treatment methods because the circulation of tissue fluid gradually recovers to normal following the recovery of tubal functions. However, it is hard to obtain long-term relief from symptoms in postirradiation OME with the usual methods because the functions of the eustachian tube recover poorly after irradiation, as discussed above. In Young's opinion, the ventilation function of the eustachian tube could recover, but damage to the cleaning function was irreversible because of the disappearance of ciliated epithelium in the nasopharynx and the atrophy of the tensor veli palatini muscle after radiotherapy for NPC. 8 We observed that liquids could flow into the nasopharynx through the eustachian tubes partly in some patients when we washed the tympanic cavities with drugs in our study. This phenomenon confirmed that the eustachian tubes were unobstructed, at least in certain patients, and fluid in the middle ears were primarily caused by tubal 
dysfunction. Additionally, only a few ears (14.1\%) were free of disease after the first treatments, regardless of the methods applied, and others needed repeated treatments These findings also indicate that functional recovery of the eustachian tube was poor.

The use of grommet insertion is controversial, primarily because of the high incidence of persistent otorrhea and eardrum perforation. However, we believe that this is not a convincing excuse to refuse this treatment option. Otorrhea and eardrum perforation after grommet insertion can be observed in all kinds of OME. The incidence is as high as $10 \%$ to $29 \%^{9}$ in children, in whom grommet insertion is most frequently used. Besides, there is no effective method to return the normal functions of the eustachian tube, so the primary purpose of treatment for postirradiation OME is the relief of symptoms to improve patients' quality of life. According to our study, grommet insertion could provide long-term relief of aural fullness and improvement in hearing level, but simple auripuncture plus aspiration could sustain only a short time relief. Thus, grommet insertion can reduce the frequency of patients' consultation and improve the quality of their lives more effectively than simple auripuncture plus aspiration. Additionally, we observed that tympanic membranes showed different pathological changes, atelectasis in different degrees, in conditions of long-term dysfunction of the eustachian tubes. If these changes cannot get effective interference as soon as possible, atelectasis can develop into adhesive otitis media and both could cause aural fullness and HL. In our study, atelectasis occurred in $18.5 \%$ of patients and adhesive otitis media in $4.4 \%$ of patients, most of whom were in group 1; the incidences in group 3 were the lowest of the three groups. Thus, the ventilation tube may play an important part in the prevention of atelectasis and adhesive otitis media in patients with NPC.

According to our observation, not all otorrhea after grommet insertion was suppurative, and some was just effusion in the middle ears. This confirmed the difference in pathogenesis between postirradiation and conventional OME. The mucosa can produce secretions continuously because of the direct irradiation damage to the middle ear, even if the ventilation tube takes the place of the eustachian tube in adjusting the pressure of the middle ear; thus, fluid in the middle ear is persistent in postirradiation OME and needs unobstructed drainage with a ventilation tube, instead of repeated auripuncture plus aspiration.

Additionally, we feel the influence of eardrum perforation should be reconsidered. Symptoms relieved or even disappeared, and satisfactory treatment results were obtained in the patients with dry eardrum perforations. Thus, the problem we should prevent and deal with is not eardrum perforation but accompanying infections. We enhanced local care with different measures, the most effective of which was washing the tympanic cavities with a mixture of $\alpha$-chymotrypsin, dexamethasone, and even antibiotics, to dilute the secretions and prevent infections.

The patients usually also have accumulated scabs, granulation tissue, and osteoradionecrosis in external acoustic meatus, rhinitis, sinusitis, etc. Thus, it is also necessary to enhance the topical care for nose, accessory nasal sinuses, and external acoustic meatus to maintain a clean environ- ment around the eustachian tube. In our study, the incidence of otorrhea and eardrum perforation after grommet insertion was $28.9 \%$, lower than that reported in the related literature, and $11.1 \%$ of patients with perforations maintained dry ears. The secretions in postirradiation OME are usually thick and turbid so that it's easy to form scabs. So we need to clear the ventilation tube or even insert it anew after cleaning under a microscope, when it is obstructed by scabs.

In addition to auripuncture plus aspiration and grommet insertion, we tried the method of tympanic membrane fenestration. In Hwang et al.'s article ${ }^{10}$, fenestration with a $\mathrm{CO}_{2}$ laser was used in OME in patients with NPC. However, we adopted drug cauterization because of limitations regarding facilities and expenses. The relief time of this method was longer than that of auripuncture, but shorter than that of grommet insertion. Compared with the latter, its advantages include a lower incidence of complications and a simpler technique.

\section{CONCLUSION}

Postirradiation OME in patients with NPC is a special kind of OME. Thus, we need not only help patients form proper expectation for the effects before treatment, but also assess results with new criteria after treatment. The three methods used here each have advantages and disadvantages. Because simple auripuncture plus aspiration usually does not cure the disease, myringotomy plus grommet insertion is still a choice for postirradiation OME, even with its high incidence of complications. In conclusion, we believe that a step by step approach should be adopted in choosing treatment methods. That is, we should use auripuncture first and then consider the other methods only if the former is inadequate. In patients with grommet insertion, enhanced local care of the middle ear can reduce the incidence of complications.

\section{BIBLIOGRAPHY}

1. Chao WY, Wang CF, Chang SJ. Ventilation tube in adults with middle-ear effusion. J Otolaryngol 1999;28:278-281.

2. Young $\mathrm{YH}$, Lin KL, Ko JY. Otitis media with effusion in patients with nasopharyngeal carcinoma, postirradiation. Arch Otolaryngol Head Neck Surg 1995;121:765-768.

3. Chen CY, Young YH, Hsu WC, Hsu MM. Failure of grommet insertion in post-irradiation otitis media with effusion. Ann Otol Rhinol Laryngol 2001;110:746-748.

4. Young YH, Lu YC. Mechanism of hearing loss in irradiated ears: a long-term longitudinal study. Ann Otol Rhinol Laryngol 2001;110:904-906.

5. Low WK. Middle ear pressures in patients with nasopharyngeal carcinoma and their clinical significance. J Laryngol Otol 1995;109:309.

6. Sadé J, Berco E. Atelectasis and secretory otitis media. Ann Otol Rhinol Laryngol 1976;85:66-72.

7. Young YH, Sheen TS. Preservation of tubal function in patients with nasopharyngeal carcinaoma, post-irradiation. Acta Otolaryngol 1998;118:280-283.

8. Young YH, Cheng PW, Ko JY. A 10-year longitudinal study of tubal function in patients with nasopharyngeal carcinoma after irradiation. Arch Otolaryngol Head Neck Surg 1997; 123:945-948.

9. Myer CM III. Post-tympanostomy tube otorrhea. Ear Nose Throat J 2001;80(Suppl 6):4-7.

10. Hwang CF, Chien CY, Lin HC, Peng JP, Chang HW, Su CY Laser myringotomy for otitis media with effusion in nasopharyngeal carcinoma patients. Otolaryngol Head Neck Surg 2005;132:924-927. 